\title{
Bolstering Corporate Sector Partnership in the Fight against Financial Crimes in the Developing World: \\ The Experience of West Africa
}

by

\author{
Dr. Abdullahi Y. Shehu
}

\begin{abstract}
Financial crime threatens the credibility and efficiency of systems and the stability of countries. Countering it requires concerted and collaborative efforts and strategic partnership between the public and private sectors. This paper discusses the roles of the private sector and challenges of compliance with acceptable international standards against money laundering and terrorist financing. The paper suggests that most of challenges, especially with regard to the reporting of suspicious transactions have almost been overcome, yet, there other challenges that remain. It concludes by making recommendations to address those challenges and improving the efficiency of the financial system.
\end{abstract}

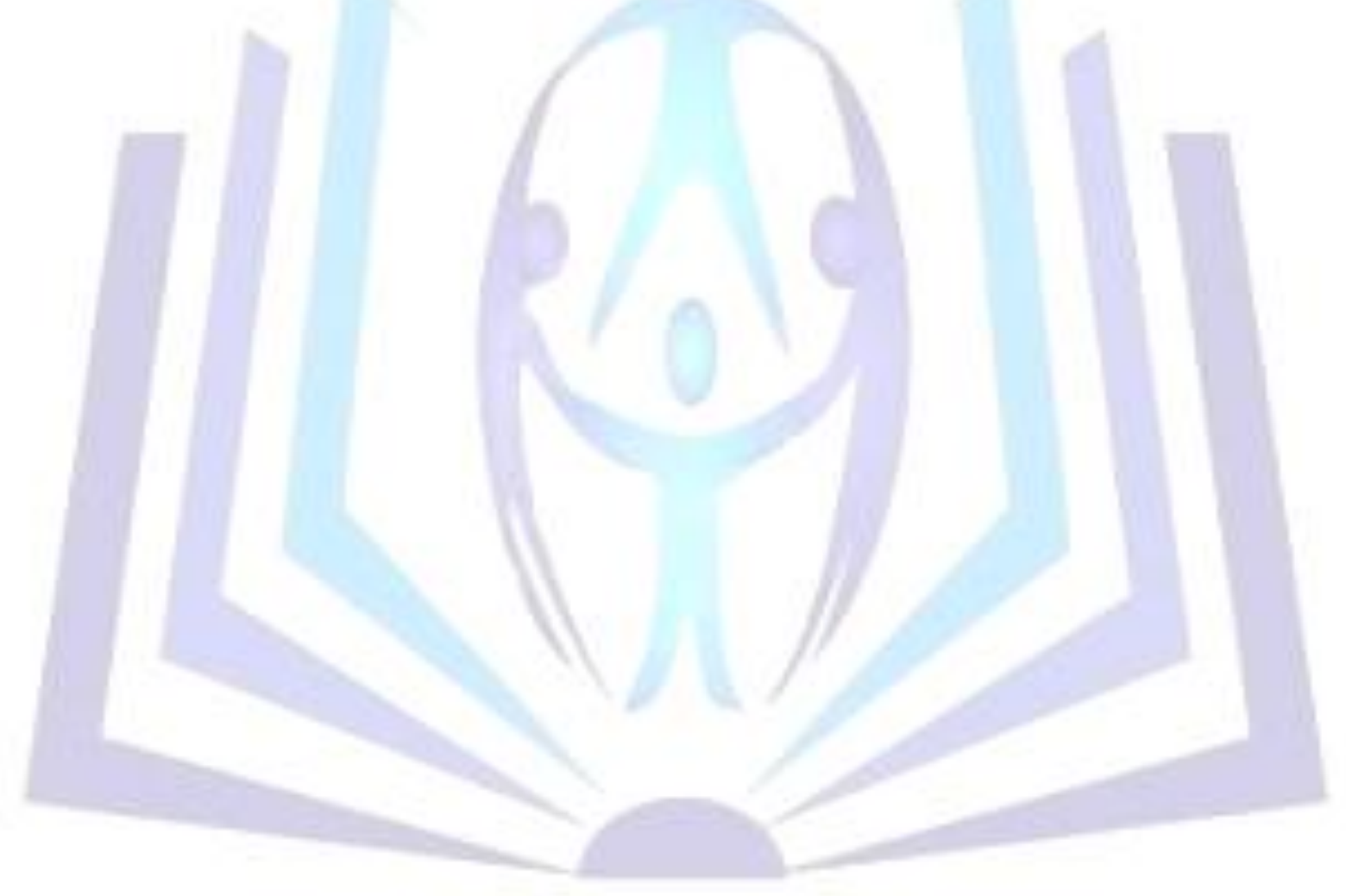

\section{Council for Innovative Research}

Peer Review Research Publishing System

\section{Journal: Journal of Social Sciences Research}

Vol. 5, No. 1

Jssreditor.cir@gmail.com

www.jssronline.com 


\section{Introduction}

This paper seeks to improve understanding of the challenges of ensuring compliance by officials of private sector entities in the developing world with global standards against serious financial crimes. It is given that the cooperation and commitment of the corporate sector is essential to the success of law enforcement against financial crimes. This is because the corporate/private sector constitutes the first line of prevention against the occurrence of financial crimes. While laws and regulations against financial crimes are made by government agencies, private sector entities such as banks, currency exchange outlets, money transfer businesses and real estate agencies, are the implementers of those laws and regulations in their daily operations. They are required to strictly comply with those laws in business relations with their clients as implementers of anti-money laundering (AML) and counter-financing of terrorism (CFT) policies, and regulations on customer due diligence (CDD), enhanced customer due diligence (ECDD), know-your-customer (KYC), as well as ongoing monitoring of politically exposed persons (PEPs).

The vigilance and proactivity of compliance officers in reporting business entities would make it difficult for criminals to launder the financial proceeds of illicit activities. In the same vein, professionals such as accountants and lawyers working to protect the businesses of their clients have an indispensible role to play in ensuring that the business activities of their principals do not breach national and international standards, laws and regulations against financial crimes, such as money laundering (ML) and terrorist financing (TF), as well as their predicate crimes. In spite of this recognition, financial crimes have continued to occur through the private sector (involving officials in the public sector in many cases), revealing flaws in the compliance systems of business organisations, as evidenced in recent high-profile scandals involving powerful multinational businesses around the world. Even without providing the details here for lack of space, suffice it to say that the infamous cases of Enron, WorldCom, Tyco, and, most recently, HSBC Bank, are fresh reminders.

Although most of the scandals have occurred, or involved multinationals with parent base, in the advanced world (USA, UK, etc), private sector compliance failures in the developing world constitutes a growing danger to global financial stability. In the first place, efforts to boost private sector compliance have advanced far beyond similar efforts in developing countries.

The banking industry self-regulation initiative of the Wolfsberg Group, for instance, reveals the extensive progress made to strengthen compliance of the banking sector in the developed world against the twin menaces of $\mathrm{ML}$ and $\mathrm{TF} .{ }^{1}$ In order to reduce the costs and cross-jurisdictional problems, and the reputational damage on account of laundering of funds for dictators, a number of banks agreed at Wolfsberg, Switzerland, in 2000 to establish a common global standard for private banking operations (i.e. for wealthy clients only). The Wolfsberg principles include common due diligence procedures for opening and keeping watch over accounts, especially those identified as belonging to 'politically exposed persons' who may combine corruption with drug money. The objective of the Wolfsberg initiative is to bring leaders of private banking to cooperate in fighting money laundering 'outside competitive business'. It is therefore a voluntary initiative of 11 major banks drawn from Germany, France, the Netherlands, Switzerland, Spain, the UK and the USA. Recently in 2002, Goldman Sachs (UK) and the Bank of Tokyo (Japan) joined the group. The participating banks were very cautious in the early days of the initiative, and after all it was a novel process whose outcome was not certain. The criteria for extending invitations to banks to join the group were on the basis of the significance of their private banking activities and also to ensure a geographic spread as far as possible. The Wolfsberg principles and experiences gained in other sectors present a lesson learned that harmonization of industry standards is not only possible but truly beneficial to business.

Hitherto, it was again the Basel Committee of Banking Supervisors and the Working Group on Bribery of the OECD which, independently of the other, took the view that more work on customer diligence should be done. Supervisors and central bankers

${ }^{1}$ See Mark Pieth and Gemma Aiolfi, Private Sector becomes active: The Wolfsberg Process 
worldwide had become increasingly concerned about the risks offshore havens posed to global financial stability, although concrete evidence for these concerns is difficult to ascertain let alone quantify.

The G8 countries have committed to ensuring that its members will have immediate access to the identity of the so-called 'beneficial owner'. ${ }^{2}$ This is good news, as the initiative will help in dismantling the wall of corporate secrecy that has shrouded spurious and unwholesome behavior of powerful western financial institutions for too long.

With close to two decades of continuous strong economic growth being recorded in developing countries, in spite of the troubling global economic recession, these countries have increasingly become the targets of transnational organized crimes and money laundering, yet the kind of concerted efforts from the developed world have not been fully replicated in the developing world. The rising economic and financial clout of the BRICS countries (Brazil, Russia, India, China and South Africa) is no more news. Nor is the impressive GDP growth rate in most African countries since the turn of the millennium. With average 5\% GDP growth since 1996 (apart from the slight dip of 2009 and 2011), Sub-Saharan Africa has performed strongly, and GDP was projected to accelerate to $5.4 \%$ in 2013 and $5.7 \%$ in $2014 .{ }^{3}$ Of all the regions of the continent, West Africa has so far been the most dynamic, topping the growth chat. GDP growth in the region is projected at $6.7 \%$ in 103 and 7.4 in 2014 , with Nigeria (7.4\%), Ghana (8\%) and Cote d'Ivoire (9\%) taking the lead. ${ }^{4}$ Weak private sector compliance in the developing world, particularly West Africa, is therefore a serious point of vulnerability to the global AML/CFT regime.

Recent incidences suggest escalating terrorist activities in the developing world. The two most visible arenas for Al-Qaida affiliate activity during 2013 have been the Sahel and the Middle East. In general, Al-Qaeda and its affiliates continue to be low cost operators, in particular when it comes to international attack plans. Only when significant territory is controlled (as had been the case in Afhanistan, Mali and Somalia before corrective military action was taken) do revenues increase significantly ${ }^{5 .}$ Emerging terrorist groups such Al Shabab, Al Qaeda in the Islamic Maghreb (AQIM), Ansar Dine and Boko Haram, have clearly shown that Africa - the poorest region of the world - is becoming the new terrorist haven. With terrorism comes terrorist financing, and it should not be a surprise that acts of violent terrorist attacks are on the rise in regions where private sector implementation of AML/CFT measures are weakest.

Other contextual factors that shape weak private sector compliance include rampant corruption, ${ }^{6}$ generally weak governance frameworks, the cash-based structure of the economies, and pervasive environment of weak regulations. It is, therefore, not a coincidence that most transnational crime and terrorist groups are based in transitional and developing countries. ${ }^{7}$ Areas of weak regulation attract more businesses and more money, and with those, more criminals. While illicit financial flows are a concern for everybody, they are of more concern in the developing world for obvious reasons: illicit financial flows from the developing world to the advanced countries strip away huge chunks of financial resources direly needed for long-term development in poor countries, undermining efforts to curb global poverty (Dev-Kar \& Cartwright-Smith 2008).

2 Emile van de D..Tearing down the walls of corporate secrecy - the G8 leads but will it follow up? Accessed at blogs.worldbank.org/psd/print/tearing-down-walls-corporate-secrecy-g8-leads-will-it-follow

${ }^{3}$ International Monetary Fund (IMF). Regional Economic Outlook - Sub-Saharan Africa. Washington, D.C.: International Monetary Fund (2013); Africa Economic Outlook, http://www.africaneconomicoutlook.org/fr/outlook/forecast/

${ }^{4}$ Africa Economic Outlook, ibid

${ }^{5}$ United Nations Security Council (UNSC) $14^{\mathrm{TH}}$ Report of the Analytical Support and Sanctions Monitoring Team, 02 August 2013, Pp 7 and 15.

6 The yearly corruption perception index published by Transparency International continues to show that the most corrupt countries are in the developing world.

${ }^{7}$ Alan Bryden and Philipp Fluri (eds) Security Sector Reform: Institutions, Society and Good Governance, 2003 
A study by Dev-Kar \& Freitas, (2012: 9) has shown that developing countries lost between US $\$ 585.9$ billion and US $\$ 918.6$ billion annually over the 10-year period 2001-2010. The same study shows that developing countries lost between US $\$ 858.8$ billion and US $\$ 1,138$ billion in the year 2010.8 When the lens is zoomed on Africa, the picture is unsettling. A most recent study by the African Development Bank (AfDB) and the Global Financial Integrity (GFI) reveal that Africa leads the rest of the developing world, having lost between US\$1.2 and US\$1.4 trillion over the 30-year period 1980-2009 through illicit financial flows (AfDB \& GFI 2013: 23). These findings confirm those of an earlier study by Dev-Kar and Cartwright-Smith (2010), covering the period $1970-2008 .{ }^{9}$

The data show that Africa is a net global creditor because illicit financial flows from the continent over the 30 -year period 1980 - 2009 grew much faster than it attracted net recorded transfers, while the net drain is about four times its total external debt (AfDB \& GFI 2013: 51).. ${ }^{10}$ The studies on illicit financial flow from Africa confirm that West and Central Africa lead the other regions of the continent in the outflow of illicit capital, with Nigeria, Congo and Cote d'Ivoire in that order, on top.

What is more troubling is that these illicit financial flows are strongly linked to underground economic activities (Dev-Kar 2010; Kar 2012; and Kar \& Freitas 2013), involving the transfer of money earned through corruption, kickbacks, tax evasion, criminal activities, transactions of contraband goods, and transfer of legal money in violation of control regulations (AfDB \& GFI 2013: 1). ${ }^{11}$ Haken (2011: i) further reveals the three (3) main forms of illicit money flowing from developing countries: bribery and theft by government officials; criminal activity; and commercial tax evasion. ${ }^{12}$ Financial crimes are, therefore, at the heart of illicit money flows from the developing world.

One of the cases that readily come to mind involved the US oil company Halliburton, which admitted that its officials had paid bribes amounting to $\$ 2.4$ million to tax officials in Nigeria in return for favourable tax treatment worth more than $\$ 14$ million. ${ }^{13}$ In another case, the same Halliburton paid \$25 million to Nigeria for bribing government officials to the tune of $\$ 180$ million in order to secure contracts in the Nigeria Liquefied Natural Gas (NLNG) in Bonny, Rivers State. ${ }^{14}$ Another multinational involved in the NLNG bribery was construction giant, Julius Berger. ${ }^{15}$ In the same vein, in early October 2007, Siemens was found guilty by a court in Munich of paying bribes worth more than 1.3bn euros to secure contracts. After being fined $201 \mathrm{~m}$ euros, further investigations revealed that 17.5 million euros of that money was paid to Nigerian

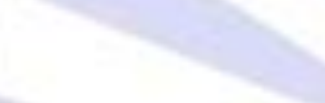

8 Dev Kar, and Devon Cartwright-Smith. Illicit Financial Flows from Developing Countries: 2002-2006. Washington DC: Global Financial Integrity, (2008); Dev Kar and Sarah Freitas. Illicit Financial Flows From Developing Countries: 2001-2010. Washington DC: Global Financial Integrity (2012)

${ }^{9}$ AfDB and GFI. Illicit Financial Flows and the Problem of Net Resource Transfers from Africa: 1980-2009. 2013; Dev Kar and Devon Cartwrigh-Smith. Illicit Financial Flows from Africa: Hidden Resource for Development. Washington DC: Global Financial Integrity (2010).

10 This is perhaps one of the reasons why the former UN Secretary General, Mr. Kofi Annan, expressed grave concern that Africa loses twice as much to illicit financial outflows as it receives in international aid. BBC News. Kofi Annan: Africa Plundered by Secret Mining. 10 May 2013. www.bbc.co.uk/news/world-africa-22478994

11 Dev Kar. The Drivers and Dynamics of Illicit Financial Flows from India: 1948-2008. Washington DC: Global Financial Integrity (2010); Dev Kar. Mexico: Illicit Financial Flows, Macroeconomic Imbalances, and the Underground Economy, Washington DC: Global Financial Integrity (2012); Dev Kar and Sarah Freitas. Russia: Illicit Financial Flows and the Role of the Underground Economy, Washington DC: Global Financial Integrity (2013)

12 Jeremy Haken. Transnational Crime in the Developing World. Washington DC: Global Financial Integrity (2011)

13 Tax Justice Network for Africa, Looting Africa: Some Facts and Figures, December 2006

14 GIABA, Corruption - Money Laundering Nexus: An Analysis of Risks and Control Measures in West Africa, Dakar, 2010; Chris Agbambu, 'Halliburton: \$25million plea bargain money disappears.' Saturday Tribune, 27 October 2012 http://www.tribune.com.ng/sat/index.php/front-page-articles/8981-halliburton-25million-plea-bargain-moneydisappears.html

15 Kingsley Omonobi, '\$180m Halliburton scandal: FG orders re-arrest of principal suspects', http://www.vanguardngr.com/2012/10/180m-halliburton-scandal-fg-orders-re-arrest-of-principal-suspects/ 
ministers or officials between 2001 and $2004 .{ }^{16}$ These cases reveal how multinational businesses operating in developing countries have encouraged a culture of private sector non-compliance with international standards against financial crimes.

Unfortunately, this movement of illicit money from the developing world is facilitated by the private sector. Dev-Kar and Freitas (2012: 19) show that, the private sector move such illicit capital from developing countries, using principally the instruments of 'trade mispricing' and 'the balance of payments.' 17 The above analysis compels the acceptance that confronting the challenges posed by private sector institutions is critical to achieving progress in the global fight against financial crimes. That is the more reason why enforcing the Risk-Based Approach (RBA) adopted by the Financial Actin Task Force (FATF) in AML/CFT should be proportionately based on the recognition of the peculiar circumstances of low capacity countries.

\section{The Compliance Challenges for the private sector in West Africa}

As the frontline of compliance with international standards against financial crimes, the corporate sector matters so much. It has been correctly pointed out that, most of the cases of complex financial crime have involved the help of bankers, lawyers and accounts - regarded as 'gate keepers' in this context all in the private sector. ${ }^{18}$ Lessons from the recent global financial crisis also demonstrate how far fraud in the private sector and the abuse of corporate vehicles could undermine global financial stability and economic prosperity. The sacking of the Chief Executives of five (5) leading banks in Nigeria in late 2009 is illustrative of the role of banks in ensuring stability and soundness of the financial system. This is also the case in many parts of developing world as in Tanzania. ${ }^{19}$

Generally, the corporate vehicles for the laundering of criminal proceeds are many as revealed in country reports received by the Inter-Governmental Action Group against Money Laundering in West Arica (GIABA) summarized in the chat below. The sector commonly used for ML purposes is the real estate, followed by the misuse of banks and the movement of cash across the borders. Others are the abuse of Designated Non Financial Institutions, Businesses and Professions (DNFBPs), misuse of the insurance and the microfinance sectors, the stocks and securities market, casinos and other gambling/games sectors. ${ }^{20}$

\section{Most common methods used for ML in GIABA member States}

\footnotetext{
16 BBC News, Nigeria probes Siemens bribe case, http://news.bbc.co.uk/2/hi/africa/7105582.stm; Tobi Soniyi, Nigeria: Bribe Scandal - Siemens Fined N7 Billion, Thisday, 22 November, 2010 http://allafrica.com/stories/201011230832.html

17 Dev Kar and Sarah Freitas, ibid

18 See Proceeds of Crime News - Money Laundering Update, Issue No. 30 (24 November 2006

${ }^{19}$ Alessandra Fontana \& Pedro Gomes Pereira, Using money laundering investigations to fight Corruption in Developing Countries: Domestic Obstacles and Strategies to overcome them. U4 Issue No. 9, November 2012, p.34 20 See GIABA Country Reports 2011
} 


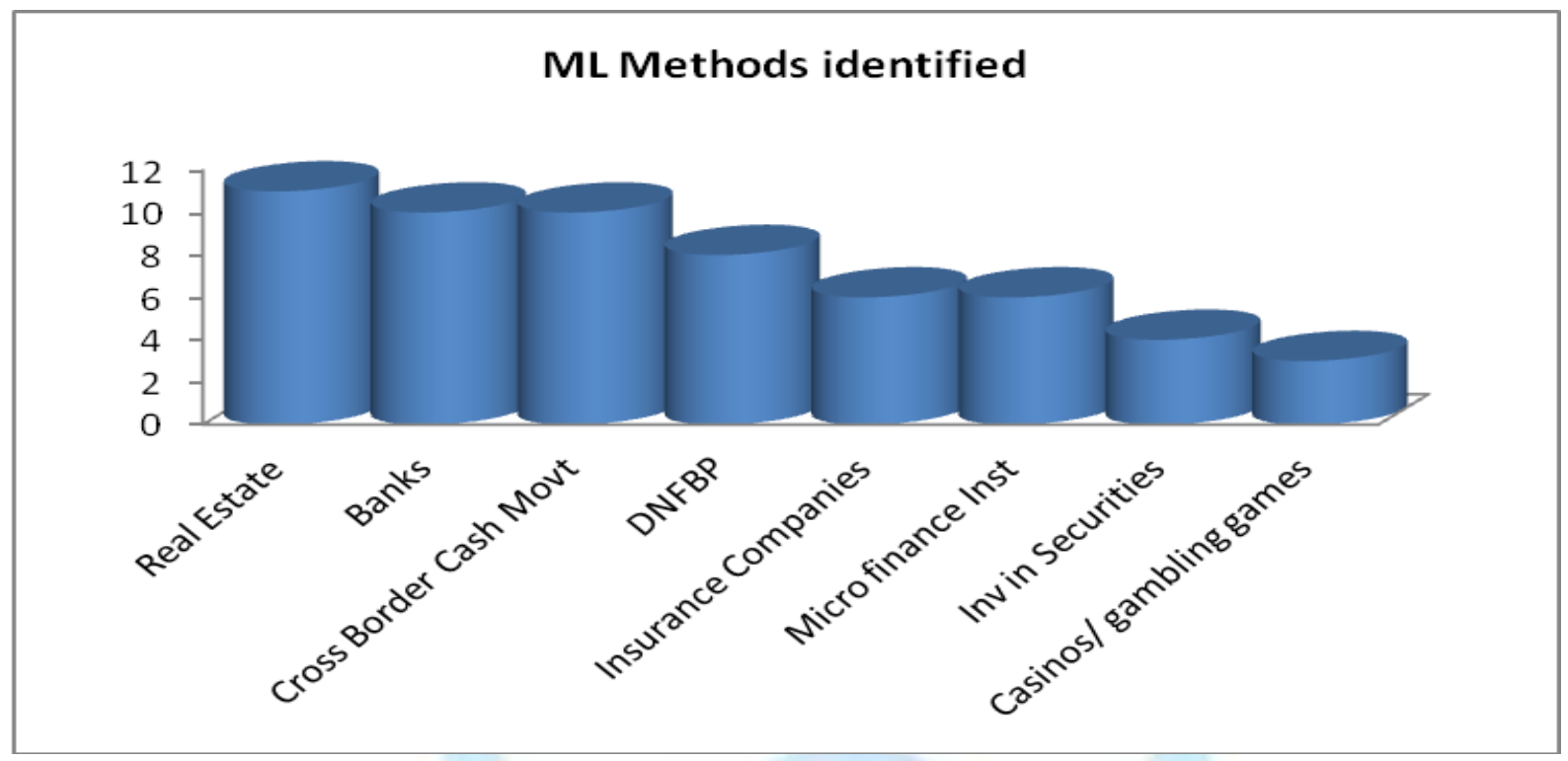

Source: GIABA Country Reports (2011)

Enforcing the law against financial crime will, therefore, fail to yield desired results unless the private sector is enabled to cooperate in a pro-active manner. However, private sector operators are out to make money, and complying with stringent regulations is costly and can seriously cut the profit margin. Private businesses are therefore not inherently inclined to comply with strict legal requirements. This is even more serious when they have to comply with strict CDD, ECDD and KYC requirements for their most valuable clients. The fear of losing those clients to other businesses in a highly competitive environment is a disincentive to private sector compliance.

One of the objective conditions for regulators to disclose suspicious transactions is the KYC principle. This is based on the risk perception of potential money laundering activity. Often financial institutions highlight the dilemma of performing enforcement responsibility. They perceive compliance as enforcement rather than their professional responsibility as bankers. This perception is, however, changing over time. The banks and other reporting entities must, for better results, share the view of a common threat or problem in order for regulation to be effective.

Unfortunately, the regulations are changing constantly. This means that banks, other reporting entities, and DNFBPs are required to upscale skills of their staff and optimize the volume of their background checks, as well as reporting to relevant authorities. With constantly changing and ever-expanding compliance requirements come ever-rising costs to private sector institutions. They now have to collect more data, do far more extensive background checks on their customers, monitor transactions more closely, increase the quality and quantity of their reporting (cash transaction reports, suspicious transaction reports, suspicious activity reports, etc), and suffer a higher risk of losing their customers who might decide to move their businesses to other jurisdictions with less strict regulations.

Consequently, the Financial Action Task Force (FATF) began to discuss the Gatekeeper Initiative, a plan to place disclosure obligations on certain professionals, such as lawyers, accountants and auditors, as far back as 1999. At the G8 Conference in Moscow in that year, a communiqué was issued which stated that

We have agreed to bring our anti-money laundering regimes in closer alignment and to consider putting certain responsibilities, as appropriate, on those professionals, such as lawyers, accountants, company formation agents, auditors and other financial intermediaries who can either block or facilitate the entry of organized crime money into the financial system. ${ }^{21}$

${ }^{21}$ Note that these categories of 'delinquent professionals' have been identified as potential intermediaries for money laundering (see FATF Typologies 2000-04). Indeed, as illustrated in these 'professionals' provide criminals with a veneer of respectability for money laundering operations. 
The peculiar context of West Africa, for example, increases the burden and cost of compliance with international standards. The most outstanding features of the region are the facts that most businesses are small and medium scale; relevant financial data on customer behavior is hard to derive; national identification systems are weak or unreliable, critical human resource capacity of most enterprises are weak, and the countries lack national mechanisms for coordinating the relationship between public (enforcement) and private (implementing) sector entities. Other factors include the lack of trust between public and private institutions, weak internal controls within private sector institutions, poor corporate governance frameworks, endemic corruption in the wider society, weak legislation, and exclusion of a large segment of the population from the financial system. ${ }^{22}$ These factors are considered in more details below.

While there are a few large banks and other financial institutions, some of which have regional and international reach, the vast majority of businesses in West Africa ranges from small to medium scale. Transactions are generally small-scale, involving saving, credit, transfer, etc. These entities therefore lack the financial power to undertake extensive and rigorous CDD and KYC, in addition to implementing ever-expanding new regulations.

Added to this is the difficulty of generating data to conduct customer background checks. Apart from information from the Financial Intelligence Unit (FIU), it is hard to find central database systems that focus on financial transactions and crimes. While such a system is important for building customer profile, its absence means that small-scale banks and other smallscale financial institutions would have to incur the cost of generating the data to enable them comply with regulatory requirements. Doing this have huge cost implications in terms of money and time, and constitute a disincentive for entities that face harsh competition.

Of all the challenges that the private sector actors face in developing countries, perhaps the most serious is the dearth of credible national identification system. Whilst it has been recognized that biometric data can help reporting entities conduct effective due diligence, this system has not been established in many countries. Like in other parts of the developing world, the countries in West Africa are at different levels of establishing and upgrading their identification systems $^{23}$. However, on the whole, the existing systems are very much limited in their usefulness to establish a comprehensive profile of customers. As in many developing countries, it is difficult to verify identity information provided by customers in many countries. Even when official documents are issued, it is still difficult to establish their genuineness from issuing authorities. The time and money it takes to authenticate each identity document provided by each customer is prohibitive to many of small and medium scale businesses. This challenge becomes ever more serious in the face of competition arising from the emergence of new payment methods, including the hawala system, which do not require extensive, rigorous identification.

The environment of pervasive corruption within which private sector financial service providers operate increases the cost of compliance for them. It is common knowledge that many developing countries are at the bottom of the corruption perception index (CPI) of the global anti-corruption watchdog, Transparency International. Many high-profile cases of corporate misdemeanor, including bribe-for-contract scandals involving foreign multinationals and government officials in Nigeria in recent years are fresh reminders. The increasingly accepted development paradigm of public-private partnership tends to reinforce corrupt practices, where cronyism and nepotism enables the so-called 'connected' businesses to circumvent the regulations and easily avoid compliance. Businesses that do not enjoy this kind of connection are at a disadvantaged position in the competition and this serves as a disincentive to compliance within the industry.

Another dimension of this is when public officials use stolen money to establish their business empires. While this in itself constitutes money laundering, such businesses use their political connection to avoid tax and perpetrate other financial crimes. The net result is high opportunity costs for similar firms that may wish to apply the rules of CDD, KYC and reporting. The serious weakness of corporate governance frameworks in developing countries makes individual compliance initiatives by businesses to face high overhead costs. Thus, efforts to streghten compliance with acceptable international standards against money laundering and terrorism financing must take into account the specific domestic circumstances and legal systems. The risk based approach contemplated here should also address measures that tend to inhibit effective compliance, including the high costs of compliance and other overly bureaucratic procedures.

Furthermore, the paucity of critical human resource capacity adds to the cost of AML/CFT compliance especially in the developing world. In the contemporary world of high-tech Internet fraud, hacking and other forms of cyber criminality, businesses in the financial sector require IT savvy professionals to effectively comply with regulatory and ethical requirements. A recent regional study on 'advance fee fraud in West Africa' conducted by GIABA shows that, over the last decade, West Africa has become a major node of global cyber fraud. ${ }^{24}$ Unfortunately, many businesses in the region lack

22 These factors were identified during a 2-day regional workshop organized for bank chief executives of the Economic Community of West African States (ECOWAS) on anti-money laundering and counter-financing of terrorism (AML/CFT) compliance by the Inter-Governmental Action Group against Money Laundering in West Africa (GIABA) in July, 2010, in Dakar, Senegal.

${ }^{23}$ One of the priorities for GIABA is to assist countries to establish a data base for strategic surveillance on predicate crimes to money laundering and this has already commenced.

${ }^{24}$ See GIABA (2012) Advance Fee Fraud in West Africa: Prevalence, Extent, Methods, Techniques, Impact and Implications for Money Laundering and Terrorist Financing. 
the capacity to hire and retain the best IT professionals to fortify their barriers against criminals. As noted by Shelley, (2003), IT experts from the developing world prefer to work in the high-tech sector in Europe and the USA, where they are highly paid, or work for criminal organisations, where they would earn far more than they would have been paid by businesses back home. Small/medium-scale businesses in the developing world therefore struggle to avoid the high cost of hiring competent professionals. When added to a pervasive low-level of sound record keeping, the net result is a situation of weak internal control within the private sector. There may be exceptional instances of sound internal control measures; however, this is a problem, which leads to low compliance with regulations.

The list of challenges, which make compliance prohibitive for private businesses in the developing world, is long. Yet, the costs driven by these challenges can be reduced if there were effective mechanisms to coordinate the relationship between the enforcement and compliance sides of national regulations and international standards against financial crimes. The private sector has to reconcile the dilemma between profit making and promoting sound financial systems with integrity to inspire or retain the confidence of their clients. Where these interests are not harmonized, businesses tend to respond by adopting the conservative approach cost-avoidance towards compliance. Rather than being willing and proactive partner for defending and protecting financial stability, some businesses have tended to save costs by 'ticking the box', reporting CTRs and STRs that are of little use for regulators and law enforcement officers.

\section{Cutting the cost of compliance}

Given the scenario above, one thing to do in order to motivate and promote the pro-active compliance of the private sector with regulations against financial crimes is to reduce the high cost of compliance. This can be approached from three obvious levels: national, regional and international. At the regional level, the Inter-Governmental Action Group against Money Laundering in West Africa (GIABA) has the mandate to strength the capacity of ECOWAS member States to effectively fight against money laundering and the financing of terrorism. Also, as the FATF Styled Regional Body (FSRB) in West Africa, GIABA has the responsibility for ensuring that member States comply with the international AML/CFT standards set by the FATF. But whatever is done at the regional level, without adequate responses at the national level, the real impact cannot be ascertained, hence GIABA is involved in an active follow up in the monitoring of compliance with the acceptable standards in its member States through a mutual evaluation process.

A key component of GIABA's private sector engagement is training and capacity building. Since its inception, GIABA has organized a series of training for compliance officers within financial institutions and for gatekeepers (DNFBPs) in the region on the FATF Recommendations and their requirements. The objective of this training is to raise the awareness of the private sector of their compliance obligations under the revised standards and to enhance their capacity to fulfill those obligations In addition, GIABA has articulated and adopted Model Compliance Manual for the financial institutions to bolster the quality of suspicious transactions in compliance with the FATF Standards.

GIABA equally recognizes the importance of industry self-regulation and has been engaging professional associations to enhance standard setting and compliance. This engagement has consisted of training of the Bar Associations and associations of chattered accountants of West African countries on the FATF Recommendations and the role they should play in ensuring the compliance of their members. GIABA has also helped to established compliance officers' associations in banks and some of reporting entities to promote cooperation and sharing of best practices. Some of the members of these Associations have been taken on study tour in Europe to learn more about effective compliance.

Furthermore, GIABA works to strengthen national coordination of the AML/CFT systems of member States. It has supported and promoted the establishment of AML/CFT Inter-Ministerial Committees in all its member States. The Committees meet regularly together with regulators and the private sector integers to discuss common problems and agree on implementation of acceptable standards.

Also, GIABA is working to promote financial inclusion in the region. Financial inclusion serves multiple purposes, including reducing the flow of unregulated money and increasing the ability of reporting entities and law enforcement to follow the money trail. GIABA recently concluded an assessment of the effect of the implementation of AML measures in financial inclusion in the region and found that promoting financial inclusion would immensely help in the prevention and control of illegal money. Similarly, a new study on the state of financial inclusion in the region is about to be conducted by GIABA. The overall goal of these studies is to support initiatives already being taken by countries within the region towards expanding the inclusion of the informal sector into the orbit of the official financial system. It is hoped that, with such expansion, the great number of businesses operating on the boundaries of the formal and informal sectors would come within the circle of compliance. The large number of financial transactions within the informal sector would be brought under the ambit of monitoring and tracking. It will also reduce the cost generating financial data on transactions that were, hitherto, difficult to capture. It is also hoped that expanded financial inclusion would considerably reduce the cost of establishing the identity of customers. In all this, developing and promoting strategic partnerships with the civil society, including private sector remains one of the main thrusts of the objectives of GIABA to bolstering a strategic partnership with the private sector and enhancing effective compliance with acceptable international standards against money laundering and terrorism financing. 


\section{Conclusion}

There is no more appropriate time than now to intensify global action towards promoting public-private partnership in battling financial crimes. Such urgent action must focus on the most vulnerable regions of the world, where financial crimes tend to have gravitated towards taking advantage of rapid economic growth and financial expansion, and where institutional weakness, poor corporate governance framework, endemic corruption, paucity of data, week national identification systems, and financial exclusion have combined to raise the cost of compliance beyond the ability of many private sector businesses to meet the ever widening requirements of regulations.

The responsibility and obligation of a financial institution - or every citizen for that matter - to disclose suspicious financial transactions should be rooted in responsible banking and a strong sense of civil society and citizenship. Responsible banking is, however, a vague concept, even in a wholly domestic environment. In an international context, the notion of bankers' responsibility is even more nebulous, and is an entirely different issue than the soundness and fiduciary prudence of the banking system (Rider 1996a-b).

The phenomenal rise of organized crime (including terrorism) in the developing world, the persistence of corruption, rapid economic and financial expansion, as well as political fragility and poor governance and weak legal systems are some of the specific domestic circumstances that must be taken into account in protecting the international financial system from abuse and misuse. National authorities, regional and international partners and businesses all have a critical role in promoting public-private partnership in such a way that makes compliance by the private sector with regulations against financial crimes attractive and affordable. In this regard, some recommendations are made in the following concluding section of this paper.

\section{Recommendations}

\section{National Authorities}

At the national level, governments have the responsibility for overall coordination of the AML/CFT systems in their countries. National authorities should, therefore, strengthen coordination of public and private sector responsibilities in fighting financial crimes. This should include promotion of communication between law enforcement and regulatory agencies, on the one hand, and private businesses, on the other. Such effective coordination would create the opportunities to harmonise the divergent interests of government and business. It would permit businesses to communicate the ever-rising cost of complying with constantly changing and expanding regulations to law enforcement officials. Equally important is the crucial need to involve the private sector institutions at the design stage of legislation and regulation so that they are aware of their compliance obligations from the outset.

The establishment and capacitation of national identification systems is also an urgent need that should be addressed by governments in developing countries, with support from international partners. An effective national identification system would eliminate the overhead costs borne by private sector institutions in ascertaining the true identity of customers for efficient compliance. Enforcing effective KYC requirements must also take into account practical reasons why identification measures do not work, especially when determining beneficial ownership.

The core problem in many jurisdictions is that the methods of conducting Know Your Customer (KYC) identification rely on information provided by the customer. As identity theft has become a feature of fraud, it might be misleading for payments and remittances systems to rely on information provided by a customer. Professional money launderers should not find it difficult to produce fake or forged documents representing their identities to surmount the obstacle of identification. In view of the flaws in KYC procedure, it would be better to develop a system of monitoring certain clients or types of transaction on the basis of risk perception rather than devoting time and resources to every individual customer for full identification. At the same time, if this is not done, the tendency is to overlook potential launderers. This is a serious dilemma that needs more thought. The challenge is to place emphasis on customer profile rather than identification details.

Linked to the above is the need to ensure the establishment of national databank on financial transactions. This is the responsibility of national governments, and it would mean that compliance institutions need not to suffer the cumbersome process of generating their own data each time on individuals each time they need to conduct background checks, CDD or ECDD on customers. This would drastically reduce compliance cost for all businesses. Governments, with support from international partners, should evolve ways of creating incentives for compliance by the private sector, and innovate means of making compliance less intrusive, costly and burdensome.

\section{Global actors}

At the global level, multinational businesses operating in develoing countries have a responsibility to show the way by supporting local small and medium-sized enterprises in fighting corruption and other financial crimes, instead of perpetrating those crimes themselves. A number of multinationals have been involved in high-profile corrupt practices by bribing government officials to secure competitive edge in recent times. 
As global actors, multinationals occupy the enviable position of championing a culture of sound corporate governance and compliance within the sector through their own business practices. By implementing robust anti-corruption programmes, covering the activities of their subsidiaries and agents in the region, they set global standards locally and help in reducing the opportunity cost of compliance by smaller local businesses.

\section{References:}

1. Alan Bryden and Philipp Fluri (2003) (eds) Security Sector Reform: Institutions,

Society and Good Governance.

2. Alessandra Fontana \& Pedro Gomes Pereira, (2012) "Using money laundering investigations to fight Corruption in Developing Countries: them". U4 Issue No. 9, November 2012, p.34

3. Dev- Kar, and Devon Cartwright-Smith (2008). "Illicit Financial Flows from Countries: 2002-2006"; Washington DC:

Global Financial Integrity, (2008).

4. Dev Kar and Devon Cartwrigh-Smith (2010). Illicit Financial Flows from Africa: Development. Washington DC: Global Financial Integrity (2010).

5. Dev Kar and Sarah Freitas (2012). "Illicit Financial Flows From Developing 001-2010”. Washington DC: Global Financial Integrity (2012).

Developing

Hidden Resource for Countries:

Transfers

6. AfDB and GFI (2013). Illicit Financial Flows and the Problem of Net Resource from Africa: $1980-2009$.

7. Emile van de D. "Tearing down the walls of corporate secrecy - the G8 leads but blogs.worldbank.org/psd/prin Accessed at down-wallscorporate-secrecy-g8-leads-will-it-follow

8. FATF (2012): "International Standards on Combating Money Laundering and the Financing Terrorism and Proliferation - The FATF

Recommendations", Paris, France.

9. GIABA (2012) "Advance Fee Fraud in West Africa: Prevalence, Extent, Methods, and Implications for Money Laundering and Terrorist Financing".

10. GIABA (2010) "Corruption-Money Laundering Nexus: An Analysis of Risks and Measures in West Africa".

11. International Monetary Fund (IMF). "Regional Economic Outlook - Sub-Saharan D.C.: International Monetary Fund (2013); Africa Economic Outlook

12. Rider, AK Barry 1996a) 'The Control of Money Laundering: A Bridge Too Far.' In the $14^{\text {th }}$ Cambridge International Symposium on Economic Crime, Jesus College, the University of Cambridge.

13. ------(1996b) 'The Practical and Legal Aspects of Interdicting the Flow of Journal of Financial Crime Control. London: Henry Stewart. 3: 3.

14. Shelley Alan (2003), 'Organized Crime, Terrorism and Cybercrime,' in Bryden \&

Techniques, Impact

Control

Africa”. Washington,

Compendium of Sector Reform: Institutions, Society and Good Baden

15. Zagari, Bruce (2007) "Problems applying traditional anti-money laundering to non-financial transactions, "Parallel Banking Systems"; in Journal of Money
Systems" and Islamic Financial Laundering Control, Volume 10, No. 2. 